\title{
Association between body mass index and chronic non-communicable diseases among the elderly chronic diseases, body mass index and elderly
}

\begin{abstract}
Objective: The aim of this study was to verify the association between body mass index (BMI) and multimorbidity in elderly.

Methods: three-hundred and ten $(\mathrm{n}=310 ; 71,62 \pm 8,15$ years $)$ subjects were recruited in a cross-sectional study in the city of Ibicuí-BA, randomly selected and enrolled to the program "Estratégia de Saúde da Família"/ "Strategy of Family health". The data were collected through self-report questionnaires and consultation of the clinical record when socio-demographic information; global health; diseases and pathologies associated; lifestyles/risk behavior and body composition were consulted.
\end{abstract}

Results: Multiple linear regression analysis revealed significant associations existing between non-communicable diseases (NCD's), multimorbidity and BMI $(\mathrm{p} \leq 0,05)$. The highest values of BMI were associated with hypercholesterolemia in women, while in men there was a correlation with hypertension.

Conclusion: The results corroborate the scientific evidence that the increased BMI is directly related to increased exposure to multimorbidity by NCD's.

Keywords: elderly, morbidity, chronic diseases, body mass index
Volume I Issue 5 - 2017

Saulo Vasconcelos Rocha,' Jorge Mota, ${ }^{2}$ Guilherme Furtado, ${ }^{3}$ Clarice Alves dos Santos, ${ }^{4}$ Estélio Henrique Martin Dantas, ${ }^{5}$ Andrée Philippe Pimentel Coutinho, ${ }^{6}$ Joao de Souza Leal Neto, ' Lélia Renata Carneiro Vasconcelos, ${ }^{8}$ Nelba Reis Souza, ${ }^{9}$ Rubens Vinícius Letieri ${ }^{10}$

'Doutor em Educação Física, Universidade Estadual do Sudoeste da Bahia, Brazil

${ }^{2}$ Professor Catedrático. Universidade do Porto, Portugal ${ }^{3}$ Mestre em Ciências do Esporte - Exercício e Saúde em Populações Especiais, Universidade de Coimbra, Portugal ${ }^{4}$ Universidade Estadual do Sudoeste da Bahia,Brazil

${ }^{5}$ Doutor Livre Docente em Educação Física, Brazil

${ }^{6}$ Mestre em educação física, Universidade Federal de Santa Catarina, Brazil

${ }^{7}$ Mestre em Educação Física, Universidade Estadual do Sudoeste da Bahia, Brazil

${ }^{8}$ Mestre em Ciências Ambientais, Universidade Estadual do Sudoeste da Bahia, Brazil

'Mestre em Atividade Física para Terceira Idade Doutoranda em Atividade Física e Saúde, Universidade de Coimbra, Portugal

${ }^{10}$ Departamento de Educação Física, Universidade Federal do Tocantins, Brazil

Correspondence: SauloVasconcelos Rocha, Doutor em Educação Física. Universidade Estadual do Sudoeste da Bahia. Rua José, Moreira Sobrinho, Jequiezinho, Jequié, Brazil, Email svrocha@uesb.edu.br

Received: June 09, 2017 | Published: July II, 2017

\section{Introduction}

The demographic profile of Latin America has changed in recent decades with an increase in the number of elderly. ${ }^{1}$ In the Brazilian context, the elderly increased the growth estimates from $9.1 \%$ in $1999^{2}$ to $12.1 \%$ in $2011 .^{3}$ This scenario favors the changes in the morbimortality profile in the country, resulting in the increased prevalence of chronic and degenerative disease ${ }^{4,5}$ and as a result a subsequent increase in expenses with public health. ${ }^{6}$

Chronic non-communicable diseases (NCD's) constitute a high problem in public health, mainly in contemporary societies. ${ }^{7}$ Estimates suggest that about 35 million people all over the world died from chronic diseases, which corresponds to the double of deaths related to infectious diseases, with an exponential increase in the elderly 7,8 population.

The imminent risk of death associated with the accumulation of NCD's becomes even more aggravating when added to some risk behaviors. ${ }^{9}$ In Brazil, the NCD's are responsible for $72 \%$ of the mortality rate representing the most important health problem of the elderly population, reaching $69,3 \%$ of the men and $80,2 \%$ of the women..$^{10}$ Being chronic processes, this group of diseases demand constant and permanent care which may lead to "decades" of use of health services in a continuous and/or intermittent way. ${ }^{11}$ The existence of two or more NCD's, a recurring situation in the elderly population, is characterized as presence of multimorbidity. ${ }^{12,13}$ Among the risk factors for the multimorbidities, obesity presents itself as one of the most important due to its exponential growth in contemporary societies. ${ }^{14,15}$ Studies that tried to associate the parental relationship and obesity prove that the risk of multimorbidity increases by 2,03 times when the individuals of both genders are obese. ${ }^{12}$

The associations between a high body mass index (BMI) related to overweight/obesity and the increase in the incidence of NCD's in the elderly population becomes increasingly evident ${ }^{16}$ The quality of nutritional intake, one of the underlying aspects of malnutrition in the elderly and low levels of physical activity, for example, appears to be associated with weight gain, with multimorbidities and it also seems to be strongly related to low socioeconomic status. ${ }^{17}$ Furthermore, susceptibility to the contraction of NCDs is directly proportional to the socioeconomic status, especially those related to cardiometabolic diseases. $^{18}$ 
NCDs, together with overweight and with low body weight are increasingly frequent situations in the elderly population..$^{19,20}$ Recent research have shown strong associations between overweight/ obesity and diabetes, ${ }^{21}$ hypertension, ${ }^{22,23}$ osteo-articular diseases ${ }^{19}$ and disabilities. ${ }^{21,24}$ On the other hand, low body weight is associated to chronic respiratory diseases and high mortality rate..$^{25}$ Limited access to primary health care, ${ }^{26}$ little control of the nutritional status in the elderly as well as the access to inappropriate drug therapies, ${ }^{27}$ are recurring aspects in the elderly and have a direct influence on the health related quality of life in the elderly person. ${ }^{28,29}$

The studies that try to establish these relationships, that use evaluation methods establishing models of association of variables in an independent and combined way ${ }^{30}$ are still uncommon, mainly among the elderly with a low socioeconomic profile. ${ }^{29}$ In spite of the existence of public primary care health services and hospital services in these regions, there's a great challenge with regard to its proper scope. Factors such as population density, low investment in areas not regarded as urban centers,${ }^{31}$ the number of health agents, ${ }^{31}$ the demand for medical services ${ }^{28}$ are all common factors to these regions and may cause differences in the health profile of these populations. In this sense, the purpose of this study was to analyze the association between body mass index and NCD's in elderly patients with low economic status.

\section{Materials and methods}

\section{Study characterization}

A cross-sectional study, ${ }^{32}$ with secondary analysis of epidemiological data, based on the population and home-based, was held in the city of Ibicuí-BA, in February 2015. The municipality of Ibicuí is located in the physiographic area of Vitória da Conquista (Encosta do Planalto) and located in the southwest of the State of Bahia, with an estimated population of 15,785 inhabitants. ${ }^{16}$ Of these, 1,153 aged 60 years or more.

\section{Size of the study sample}

The target population of this study consisted of individuals aged 60 years nd over, registered by the Community Health program 'Family Health Strategy' (FHS). To determine the size of the sample we used the criteria for finite populations proposed by Luiz \& Magnanini, ${ }^{17}$ being adopted for these calculations a significance level of $5 \%$ (confidence interval of $95 \%$ and tolerable error of $3 \%, z[a] / 2=1.96$ ). At the end of the sample calculus $10 \%$ more individuals were included in the sample to compensate for possible sample losses. The selection was performed randomly in a ratio of $1: 2$, i.e. for three selected medical inventories, one participant was included in the study and two deleted. To do this, we used the Epi Info 6.4 software, with a representative sample of elderly enrolled in the health services of the municipality and proportional distribution by age and sex. The initial sample was composed by 1.146 elderly that after the application of the sample selection criteria (described below) and subsequent stratification by the above random method reached the final sample composed by 310 elderly of both genders. The figure describes the path for sample selection as well as the frequency of the response rate of the study participants.

\section{Data collection}

Data collection was performed by a team of trained research assistants previously prepared for this purpose. Through phone calls conducted by research assistants, the participant was signaled to attend a routine medical appointment. Moreover, home visits were made by research assistants as one of the ways for collecting the data for the study, when the elderly had difficulties to go to the HFU in the month of collection. Research assistants provided assistance to some elderly, by reading documents aloud; running record of the options of response desired by the participants and was trained not to issue any judgment on the response options of the research participants.

\section{Sample selection criteria}

Inclusion criteria: To participate in the study spontaneous and voluntarily, after reading the consent and explanation term on the objectives of the research research; to be 60 or more and of both genders; to be enrolled in the FHS's that are participating in the study and take part in the study spontaneously. As for the exclusion criteria they were: withdraw from the study bedridden elderly, patients with dementia, Alzheimer's disease, Parkinson's or other neurodegenerative disease, elderly people with vision problems and severe hearing. Elderly people with another place of residence, absence of the residence after 3 consecutive visits or missing 3 appointments at the health unit and direct refusals were withdrawn from the sample.

\section{Measurements}

The collection of the information was performed by instruments validated according to the Brazilian reality and also, through a questionnaire of biosocial nature, of semi-structured type developed for this purpose. The information was obtained in the form of selfadministration. However, in some cases where inconsistency in the speeches was detected, consultation was held to recall/medical records of the participant provided by the local nurse to prove the veracity of the obtained data. Information was included about the health risk behaviors, lifestyles, socio-demographic indicators and the NCDs, based on the conceptual guidelines of the multidimensional model of life quality related to health according to the World Health Organization. The objective parameters were obtained through appropriate collection instruments; all described in the topics that follow.

\section{Dependent variable}

Chronic Non-Communicable diseases: we included the stroke, diabetes mellitus, hypertension, cancer, high cholesterol, chronic lung disease, asthma/bronchitis, other respiratory diseases (eg: allergies.), coronary heart disease, rheumatism, common mental disorders.

\section{Independent variable}

Body mass index; Body composition: Body mass was measured with a portable digital scale $(\mathrm{OMRON} \otimes)$ and to evaluate the height a stadiometer (brand Sanny ${ }^{\circledR}$ ) was used, both calibrated for measurements. BMI, evaluative measure used with indicator of nutritional status was obtained through the assessment of body mass and height, calculated by the formula [BMI = body weight $(\mathrm{kg}) /$ height $2(\mathrm{~m})$ ], whose procedure followed a standardized protocol. ${ }^{33}$

\section{Model adjustment variables}

Sociodemographic variables: gender (male and female), age (continuous variable), education level ('literate' and 'illiterate'), living arrangements ('live with' or 'unmarried'). Analysis of lifestyles and health risk behaviors, the following information was computed: 
daily consumption of alcoholic beverages ('yes' or' no '), smoking (' ever smoked, 'never smoked', 'currently smoking') and level of physical activity during leisure time (answer 'yes': mild, moderate or severe, 'not' I do not do any physical activity in leisure time). Presence of Common Mental Disorders (CMD) was used the SelfReporting Questionnaire (SRQ-20). The SRQ-20 is the version of 20 items of SRQ-30 for screening non-psychotic mental disorders; the responses are dichotomous yes / no. Each affirmative response scores to the value of one (1) to compose the final score of the scale, obtained by the sum of these values. In the TMC classification, it was adopted the cutoff of five or more positive responses. ${ }^{34}$

Non communicable chronic deseases: they were defined from the NCD's number. the rate of occurrence was found by a question with two answer choices being the yes indicative of two or more diseases and conditions and the answer 'no' option for the occurrence of one disease or none..$^{35,36}$

Waist circumference: The waist circumference was measured using inelastic tape, measured at the narrowest part of the abdomen or the midpoint between the last rib and the iliac crest. Reference Manual procedures were followed for standardization of anthropometric measurements. ${ }^{33}$

\section{Statistic procedures}

As a preliminary procedure, we proceeded to the introduction of data which were twice retyped and validated in the computer program Epi Info 6.04 developed by the Center for Disease Control and Prevention, Atlanta-United States ${ }^{37}$ For the descriptive analysis, the proportions of individuals depending on the categories, expressed in percentages, according to the variable analyzed. The evaluation of the differences between the genders in the descriptive variables was performed using the chi-square test. To correct the effects of the covariates and test the influence of the independent variables, the association between BMI and NCD's was performed by multiple linear regression analysis (CI: 95\%). To this end, were considered three regression models using the BMI as a reference variable. The models were built considering the quality of life construct related to health of the WHO. ${ }^{38}$ Associations between BMI and NCD's whose matrix comprises the adjustment through the variables age, family structure and education were explored in model 1 . Model 2 includes the variables age and education, family structure, smoking, waist circumference, physical activity and alcohol consumption. The model 3 has an adjustment matrix that considered all of the above variables, including the assessment of multimorbidities. BMI values were analyzed as a continuous variable. In all analyzes we used a significance level of $5 \% .{ }^{39,40}$ Data were analyzed using the statistical program SPSS 22.00.

\section{Ethical procedures}

All procedures were previously avaliated and approved by Ethical Committee of Universidade Estadual do Sudoeste da Bahia (CAAE: 22969013.0.0000.0055). This study followed the statment of ethical principles presented on Declaration of Helsinki ${ }^{41}$ and on the resolution law n ${ }^{\circ} 466 / 2012$ of National Commitee of Health to conduct research with humans. ${ }^{42}$

\section{Results}

Among respondents the average age was $71.62 \pm 8.15$ years. There was a higher percentage of women (56.5\%), individuals aged $60-79$ years $(83.9 \%)$, literacy $(56.1 \%)$, living without a partner $(51.0 \%)$ and in a state of co-residence $(78.4 \%)$. The average monthly income of the investigation was R $\$ 708.26 \pm 303,69$ reais. With regard to lifestyle, most said they do not consume alcohol daily (95.8\%), and reported not currently smoking $(88.4 \%)$. Regarding the level of physical activity during leisure time, $68.7 \%$ of the elderly were inactive in their free time.

As to those diseases, $13.5 \%$ of seniors referred heart disease, $64.2 \%$ had hypertension, $31 \%$ had hypercholesterolemia and $24.8 \%$ with circulatory diseases. The overall prevalence of multimorbidity was $80.3 \%$, it was identified higher prevalence of multimorbidity among elderly women $(73.7 \%)$ against $45.9 \%$ male.

Table 1 shows the results of the crude analysis of the associations between chronic diseases and body mass index for men and women. In women, BMI was $1.90 \mathrm{~kg} / \mathrm{m}^{2}$ higher for those with hypertension and $1.74 \mathrm{~kg} / \mathrm{m}^{2}$ times higher for those with hypercholesterolemia $2.94 \mathrm{~kg} /$ $\mathrm{m}^{2}$ times greater for those with circulatory diseases and $2.63 \mathrm{~kg} / \mathrm{m}^{2}$ times higher for those who reported a diagnosis of rheumatism. In men, only hypertension was associated with BMI (Table 1).

Table I Multiple linear regression, between each chronic disease and body mass index according to the sex of the participants $(\mathrm{n}=3 \mathrm{I} 0)$

\begin{tabular}{|c|c|c|c|c|}
\hline & \multirow{2}{*}{$\begin{array}{l}\text { Women(N= I75) } \\
\text { B (Cl:95\%) }\end{array}$} & \multicolumn{2}{|c|}{ Men $(\mathrm{N}=135)$} & \multirow[b]{2}{*}{$\mathbf{P}$} \\
\hline & & $\mathbf{P}$ & B (Cl:95\%) & \\
\hline High Blood Pressure & I,90 $(0,207 ; 3,60)$ & 0,028 & $1,43(0,09 ; 2,76)$ & 0,036 \\
\hline Diabetes mellitus & $0,79(-1,64 ; 3,22)$ & 0,523 & $0,16(-161 ; 1,94)$ & 0,852 \\
\hline Asthma and bronchitis & $-0,42(-3,68 ; 2,83)$ & 0,797 & $1,38(-3,13 ; 5,90)$ & 0,545 \\
\hline Stroke & $0,05(-3,20 ; 3,32)$ & 0,972 & I,09(- I,57; 3,76) & 0,417 \\
\hline Other Respiratory diseases & $-1,25(-2,88 ; 0,38)$ & 0,133 & $-0,63(-2,09 ; 0,83)$ & 0,395 \\
\hline Hypercholesterolemia & $\mathrm{I}, 74(0,20 ; 3,28)$ & 0,027 & I,I2 (- 0,7I;2,95) & 0,228 \\
\hline Choronary Heart Disease & $2,94(1,29 ; 4,59)$ & $<0,001$ & $-0,53(-2,20 ; 1,13)$ & 0,527 \\
\hline Rheumatism & $2,63(1,04 ; 4,22)$ & $<0,00$ I & $-0,98-(2,44 ; 0,46)$ & 0,182 \\
\hline Common Mental Disorders & $0,79(-0,86 ; 2,45)$ & 0,345 & $-1,28(-2,63 ; 0,05)$ & 0,060 \\
\hline
\end{tabular}

$(* * \mathrm{p} \leq 0.00 \mathrm{I} ; \mathrm{*} \leq 0.005 *) ; \mathrm{Cl}$ : Confidence Interval. 
Table 2 shows the results of the adjusted analysis of the associations between NCD's and BMI for women. Considering the model 1 adjustment variables (age, family structure, and education), the association between the higher BMI and chronic diseases were kept. In the adjustment of model 2 (age, education, family structure, smoking, waist circumference, alcohol consumption and physical activity), hypertension, circulatory diseases and rheumatism lost magnitude of association in the BMI. In the final model, only hypercholesterolemia was independently associated with BMI.

Among men, when related to BMI and the three models in the regression analysis, only the 'blood pressure' remained associated with increased BMI (Table 3).

Table 2 Multiple linear regression analysis between body mass index and non-communicable chronic diseases in women, adjusted for the three models $(\mathrm{n}=175)$

\begin{tabular}{|c|c|c|c|c|c|c|}
\hline & \multicolumn{2}{|l|}{ Model I } & \multicolumn{2}{|l|}{ Model 2} & \multicolumn{2}{|l|}{ Model 3} \\
\hline & $\beta(\mathrm{Cl}: 95 \%)$ & $\mathbf{P}$ & $\beta(\mathrm{Cl}: 95 \%)$ & $\mathbf{P}$ & $\beta(\mathrm{Cl}: 95 \%)$ & $\mathbf{p}$ \\
\hline High Blood Pressure & $\mathrm{I}, 85(0,16 ; 3,55)$ & 0,031 & $-0,80(-0,97 ; 0,8 I)$ & 0,860 & $-0,53(I, 49 ; 0,42)$ & 0,273 \\
\hline Diabetes mellitus & $0,66(-1,80 ; 3,13)$ & 0,596 & $0,12(-1,14 ; 1,36)$ & 0,860 & $0,04(-1,26 ; 1,34)$ & 0,951 \\
\hline Asthma e bronchitis & $-0,69(-3,94 ; 2,56)$ & 0,675 & $-1,30(-2,94 ; 0,32)$ & 0,116 & $-1,25(-2,99 ; 0,49)$ & 0,158 \\
\hline Stroke & $0,17(-3,08 ; 3,42)$ & 0,916 & $0,14(-1,52 ; 1,81)$ & 0,865 & $0,12(-1,55 ; I, 8 I)$ & 0,881 \\
\hline Other Respiratory diseases & $-1,32(-2,97 ; 0,32)$ & 0,114 & $-0,26(-1,13 ; 0,60)$ & 0,547 & $-0,37(-1,32 ; 0,58)$ & 0,442 \\
\hline Hypercholesterolemia & $\mathrm{I}, 6 \mathrm{I}(0,56 ; 3,17)$ & 0,042 & $0,96(-0,14 ; 1,77)$ & 0,021 & $\mathrm{I}, 0 \mathrm{I}(0, \mathrm{II} ; \mathrm{I}, 90)$ & 0,027 \\
\hline Choronary Heart disease & $2,80(I, 14 ; 4,46)$ & $<0,00$ I & $0,75(-0,17 ; 1,68)$ & 0,109 & $0,72(-0,28 ; 1,72)$ & 0,159 \\
\hline Rheumatism & $2,73(1,07 ; 4,39)$ & $<0,00$ I & $0,68(-0,21 ; 1,58)$ & 0,135 & $0,33(-0,64 ; 1,30)$ & 0,506 \\
\hline Common Mental Disorders & $0,7 \mid(-0,94 ; 2,37)$ & 0,395 & $0,0 \mathrm{I}(-0,84 ; 0,87)$ & 0,969 & $-0,09(-0,98 ; 0,79)$ & 0,829 \\
\hline
\end{tabular}

$\left(* *_{p} \leq 0.00\right.$ I * 50.005$)$; BM, confidence interval; multiple regression model I, adjustment for age + family arrangement + education - Model 2 , adjustment for age + education + family arrangement + smoking + waist circumference + alcohol + physical activity - Model 3 adjustment for all of the above variables and for all diseases and disorders

Table 3 Multiple linear regression analysis between body mass index and chronic non-communicable diseases in males, adjusted for the three models $(n=135$ )

\begin{tabular}{|c|c|c|c|c|c|c|}
\hline & \multicolumn{2}{|l|}{ Model I } & \multicolumn{2}{|l|}{ Model 2} & \multicolumn{2}{|l|}{ Model 3} \\
\hline & $\beta(\mathrm{Cl}: 95 \%)$ & $\mathbf{p}$ & $\beta(\mathrm{Cl}: 95 \%)$ & $\mathbf{p}$ & $\beta(\mathrm{Cl}: 95 \%)$ & $\mathbf{p}$ \\
\hline High Blood Pressure & $\mathrm{I}, 30(0, \mathrm{II} ; 2,59)$ & 0,048 & $\mathrm{I}, \mathrm{I} 6(0,1 \mathrm{I} ; 2,2 \mathrm{I})$ & 0,030 & I,39(0,22; 2,55) & 0,020 \\
\hline Diabetes mellitus & $0,44(-1,26 ; 2,14)$ & 0,608 & $0,02(-1,35 ; 1,40)$ & 0,973 & $-0,19(-1,66 ; 1,28)$ & 0,797 \\
\hline Asthma e bronchitis & $2,85(-1,54 ; 7,25)$ & 0,201 & $0,90(-2,75 ; 4,56)$ & 0,625 & I,74(- 2,05; 5,54) & 0,366 \\
\hline Stroke & $0,81(-1,73 ; 3,36)$ & 0,530 & $-0,02(-2,10 ; 2,06)$ & 0,985 & $-0,53(-2,73 ; 1,66)$ & 0,631 \\
\hline Respiratory diseases & $-0,36(-1,79 ; 1,06)$ & 0,612 & $-0,26(-1,42 ; 0,90)$ & 0,659 & $-0,66(-1,91 ; 0,59)$ & 0,297 \\
\hline Hypercholesterolemia & $0,78(-0,99 ; 2,55)$ & 0,385 & $0,24(-1,20 ; 1,68)$ & 0,744 & $0,5 \mathrm{I}(-1,06 ; 2,09)$ & 0,517 \\
\hline Choronary Heart diseases & $-0,27(-1,89 ; 1,35)$ & 0,741 & $-0,31(-1,64 ; 1,01)$ & 0,643 & $-0,57(-2,08 ; 0,93)$ & 0,452 \\
\hline Rheumatism & $-0,53(-1,94 ; 0,88)$ & 0,457 & $-0,60(-1,75 ; 0,53)$ & 0,295 & $-0,58(-1,89 ; 0,72)$ & 0,378 \\
\hline Common Mental Disorders & $-0,754(-2,08 ; 0,57)$ & 0,263 & $0,36(-0,74 ; 1,47)$ & 0,518 & $0,55(-0,64 ; ।, 76)$ & 0,360 \\
\hline
\end{tabular}

$\left(*^{*} \mathrm{p} \leq 0.00 \mathrm{I} * \mathrm{p} \leq 0.005^{*}\right) ; \mathrm{Cl}$, confidence interval; Multiple Regression Model I, adjusted for age + family arrangement + education; Model 2 , adjustment for age + education + family arrangement + smoking + waist circumference + alcohol + physical activity; Model 3 , adjustment for all of the above variables and to all diseases and disorders

Figure 1 shows the trend graph for NCD's number and BMI for men and women. The BMI of women with 2 or more of the diseases was slightly higher compared to those with 1 or no disease. For men,

the BMI of those with 2 or more diseases was higher than that of individuals reporting no or 1 disease. 


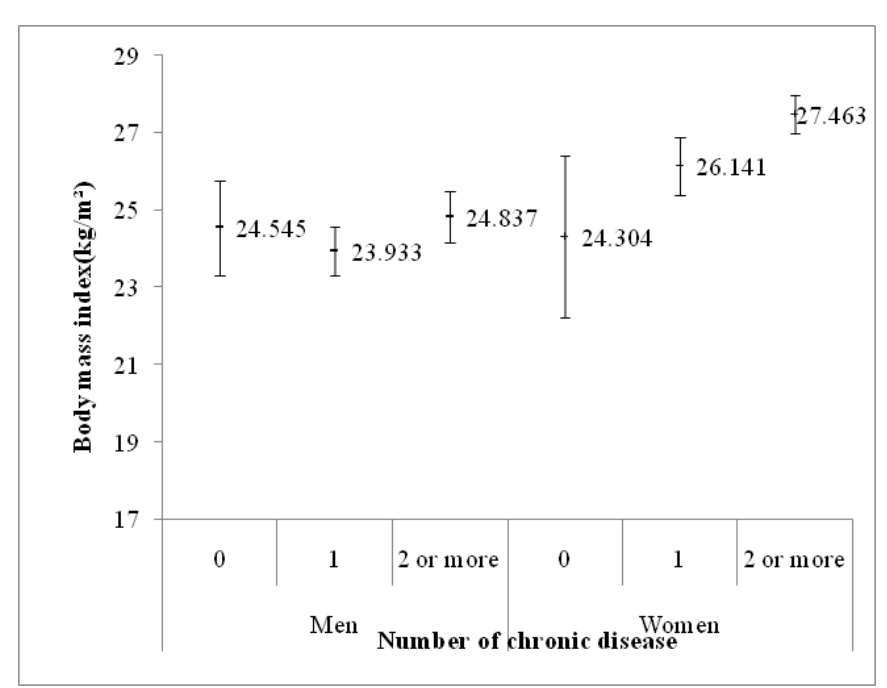

Figure I Graph of the mean analysis of the BMI and assessment of NCD's analyzed by gender of the participants.

\section{Discussion}

This is one of the few studies carried out in Brazil in which the epidemiological survey seek to analyze the association between NCD's, socio-demographic indicators, risk behavior factors and lifestyle nutritional status (BMI) in elderly with low economic status. Very common in epidemiological studies, the obtainance of selfreported health data may not guarantee their reliability, ${ }^{18}$ so the option for direct consultation to the doctoris files in cases where the elderly had doubts.

Our results showed significant differences between genders in the estimates of NCDs and in the association between NCDs, multimorbidities and BMI. Among females, hypercholesterolemia remained associated with higher BMI. While among men, hypertension was associated with higher BMI after the multivariate analysis. Moreover, there was a significant linear relationship between the number of diseases and BMI for men and women, revealing a trend of more NCDs among individuals with higher BMI scores.

Independently from the analyzes by gender, it is quite clear that in this study sample, the BMI seems to establish a direct relationship with the group of cardiometabolic diseases. The differences in the association between gender, NCDs and BMI observed in this study corroborate the findings in recent studies. ${ }^{43,44}$

Epidemiological studies show differences in distribution of NCDs in genders, ${ }^{34,35}$ with a higher prevalence of chronic diseases among women. ${ }^{45,46}$ Aspects such as greater demand for health services and longer life expectancy, may contribute to greater presence of chronic diseases among women. ${ }^{47}$ After the adjusted analysis, hypercholesterolemia remained associated with higher BMI values for women. Study results from Framingham show that the increase in total body fat related to aging, increases the likelihood of metabolic disorders such as the increase in glucose and hypercholesterolemia. ${ }^{48}$ Among men, independently from behavioral, sociodemographic factors and presence of other NCDs, hypertension remained associated with higher BMI scores. A recent study with elderly population in the city of São Paulo showed that BMI was strongly associated with high blood pressure, which was similar to the findings of the present study. ${ }^{22}$
The authors also identified that the elderly male with a BMI $\geq 27 \mathrm{k} / \mathrm{m}^{2}$ is $85 \%$ more likely to develop high blood pressure compared to those with $\mathrm{BMI}<27 \mathrm{~kg} \mathrm{~m}^{2}$. The information collected in this study slightly contrasts with the statement that in the elderly a higher BMI value is directly related to lower risk of mortality. ${ }^{49}$

The high BMI has been associated with risk factors for blood hypertension. ${ }^{23}$ Individuals with higher BMI scores show physiological changes in the sympathetic nervous system, reninangiotensin-aldosterone system, endothelial dysfunction and functional abnormalities. ${ }^{23,22,50}$ These modifications increase the exposure to hypertension and cardiovascular disease, which can certainly be explained by the increased of the body fat mass. ${ }^{50,22}$ Although not significant, there was a significant correlation from the clinical point of view between the number of diseases and BMI in men and women. In individuals of both genders the average BMI was higher among those who reported two or more diseases, regardless of the adjustment variables.

The findings about the relationship between multimorbidities and BMI with representative samples still present reduced numbers, only one population study carried out by adults in the UK identified this relationship quite clearly showing a prevalence of multimorbidity of $23 \%$, increasing with the increase of BMI, reaching $44 \%$ in subjects with class II obesity, suggesting that multimorbidities may result from overweight/obesity. ${ }^{16}$

Although multimorbididity presents itself as a public health problem, it has a negative impact on quality of life of the elderly, ${ }^{24,47}$ it can be noted that the possible mechanisms involving the relationship between multimorbidities with some risk factors such as BMI are still not fully understood. ${ }^{51,52}$ However, from the results found and the evidence from literature it appears that increasing BMI is directly related to increased exposure to NCDs morbi-mortalities. Aspects such as low economic status, low education, poor diet, sedentary lifestyle, poor access to primary health care are conditions that may increase the magnitude of this association.

Among the study's limitations, we can highlight the methodological design, as the cross-sectional study does not allow assessment of the cause and effect between the variables. Recall bias may have influenced the response variable diseases mentioned; however, this measure is widely used in epidemiological studies as an indicator of health status, especially in older people, as well as reported in other researches, ${ }^{18}$ which favors the comparison between studies. ${ }^{18}$ However, it is necessary to emphasize that this research was conducted with a little investigated population in Brazil, generating important information for health policy and clinical practice of professionals who care for the health of the elderly population.

\section{Conclusion}

The highest values of BMI were associated with hypercholesterolemia in women, while in men there was a correlation with hypertension. The highest means of BMI were identified among individuals with higher number of diseases. The results corroborate the scientific evidence that the increased BMI is directly related to increased exposure to multimorbidity by NCD's. ${ }^{53-59}$

\section{Acknowledgements}

We thank the Municipal Government of Ibicui for the contribution to the study 


\section{Conflict of interest}

Authors declare there is no conflict of interest in publishing the article.

\section{References}

1. Envejecimiento y salud: un cambio de paradigma. Rev Panam. Salud Pública 7(1): 60-67.

2. Garrido R, Menezes, PRO. Brasil está envelhecendo: boas e más notícias por uma perspectiva epidemiológica. Rev Bras Psiquiatr. 2002;24(1):3-6.

3. Küchemann BA. Envelhecimento populacional, cuidado e cidadania: velhos dilemas e novos desafios. Soc. e Estado. 2012;27(1):165-180.

4. Nascimento Cde M, Ribeiro AQ, Cotta RM, et al. Factors associated with functional ability in Brazilian elderly. Arch Gerontol Geriatr. 2012;54(2):89-94.

5. Guerreiro RJ, Santana I, Brás JM, et al. Peripheral inflammatory cytokines as biomarkers in Alzheimer's disease and mild cognitive impairment. Neurodegener Dis. 2007;4(6):406-412.

6. Silveira RE, Santos Á, S Sousa, et al. Gastos relacionados a hospitalizações de idosos no Brasil: perspectivas de uma década. Einstein (São Paulo). 2013;11(4):514-520.

7. WHO. Strategy and action plan for healthy ageing in Europe. World Health Organization, Europe; 2012.

8. World Health Organization. Interventions on Diet and Physical Activity: What Works. Summary report. 2009.

9. Romo-Perez V, Souto D, Mota J. Walking, body mass index, and selfrated health in a representative sample of Spanish adults. Cad Saude Publica. 2016;32(1):102-311.

10. Schmidt MI, Duncan BB, Silva GA, et al. Chronic non-communicable diseases in Brazil: burden and current challenges. Lancet. 2011;377(9781):1949-1961.

11. Canella DS, Novaes HM, Levy RB. [The influence of excess weight and obesity on health spending in Brazilian households]. Cad Saude Publica. 2015;31(11):2331-2341.

12. Taylor AW, Price K, Gill TK, et al. Multimorbidity - not just an older person's issue. Results from an Australian biomedical study. BMC Public Health. 2010;22(10):718.

13. Diederichs C, Berger K, Bartels DB. The measurement of multiple chronic diseases--a systematic review on existing multimorbidity indices. J Gerontol A Biol Sci Med Sci. 2011;66:301-311.

14. Agborsangaya CB, Ngwakongnwi E, Lahtinen M, et al. Multimorbidity prevalence in the general population: the role of obesity in chronic disease clustering. BMC Public Health. 2013;10(13):1161.

15. Batsis JA, Mackenzie TA, Barre LK, et al. Sarcopenia, sarcopenic obesity and mortality in older adults: results from the National Health and Nutrition Examination Survey III. Eur J Clin Nutr. 2014;68(9):1001-1007.

16. Booth HP, Prevost AT, Gulliford MC. Impact of body mass index on prevalence of multimorbidity in primary care: cohort study. Fam Pract 2014;31(1):38-43.

17. Ruel G, Shi Z, Zhen S, et al. Association between nutrition and the evolution of multimorbidity: the importance of fruits and vegetables and whole grain products. Clin Nutr. 2014;33(3):513-520.

18. Pimenta FB, Pinho L, Silveira MF, et al. Factors associated with chronic diseases among the elderly receiving treatment under the Family Health Strategy. Cien Saude Colet. 2015;20(8):2489-2498.
19. Fares D, Barbosa AR, Borgatto AF, et al. Fatores associados ao estado nutricional de idosos de duas regiões do Brasil. Rev Assoc Med Bras. 2012;58(4):434-441.

20. Silveira EA, Dalastra L, Pagotto V. Polypharmacy, chronic diseases and nutritional markers in community-dwelling older. Rev Bras Epidemiol. 2014;17(4):818-829.

21. Tyrovolas S, Koyanagi A, Garin N, et al. Diabetes mellitus and its association with central obesity and disability among older adults: A global perspective. Exp Gerontol. 2015;64:70-77.

22. Munaretti DB, Barbosa AR, Marucci MFN, et al. Hipertensão arterial referida e indicadores antropométricos de gordura em idosos. Rev Assoc Med Bras. 2011;57(1):25-30.

23. Leal Neto Jde S, Coqueiro Rda S, Freitas RS, et al. Anthropometric indicators of obesity as screening tools for high blood pressure in the elderly. Int J Nurs Pract. 2013;19(4):360-367.

24. Danielewicz AL, Barbosa AR, Del Duca GF. Nutritional status, physical performance and functional capacity in an elderly population in southern Brazil. Rev Assoc Med Bras. 2014;60(3):242-248.

25. Ferreira LS. Undernutrition as a major risk factor for death among older Brazilian adults in the community-dwelling setting: SABE survey. Nutrition. 2011;27:1017-1022.

26. Carvalho AT, Deborah CM, Marilisa Berti AB, et al. [Inequalities in selfrated health: an analysis of the Brazilian and Portuguese populations]. Cad saúde pública. 2015;31(11):2449-2461.

27. Martins GA, Acurcio FA, Franceschini SCC, et al. [Use of potentially inappropriate medications in the elderly in Viçosa, Minas Gerais State, Brazil: a population-based survey]. Cad saúde pública. 2015;31(11):2401-2412.

28. Kassouf AL. Acesso aos serviços de saúde nas áreas urbana e rural do Brasil. Rev Econ e Sociol Rural. 2005;43(1):29-44.

29. Azevedo EC, Diniz AS, Monteiro JS, et al. Padrão alimentar de risco para as doenças crônicas não transmissíveis e sua associação com a gordura corporal - uma revisão sistemática. Cien Saude Colet. 2014;19(5):1447-1458.

30. Brigola AG, Rossetti ES, Santos BR, et al. Relationship between cognition and frailty in elderly: A systematic review. Dement neuropsychol. 2015;9(2):110-119.

31. Venturi I. Identificação da área de influência do serviço de atenção básica do sistema público de saúde à população idosa, município de ViçosaMG. Cien Saude Colet. 2008;13(4):1293-1304.

32. Jerry Thomas, Jack Nelson, Stephen Silverman. Research Methods in Physical Activity, 7th edn. Human Kinetics. Europe; 2015.

33. LohmanTG, Roche AF, Martorell R. Anthropometric standardization reference manual. Med Sci Sport Exerc. Europe; 1988.

34. Borim FSA, Barros MBA, Botega NJ. Transtorno mental comum na população idosa: pesquisa de base populacional no Município de Campinas, São Paulo, Brasil. Cad. Saude Publica. 2013;29(7):1415-1426.

35. Campos MR, von Doellinger Vdos R, Mendes LV, et al. Morbidity and mortality associated with injuries: results of the Global Burden of Disease study in Brazil, 2008. Cad. Saude Publica. 2015;31(1):121-136.

36. Roberts J, Lenton P, Keetharuth $\mathrm{AD}$, et al. Quality of life impact of mental health conditions in England: results from the adult psychiatric morbidity surveys. Health Qual Life Outcomes. 2014;12(6).

37. Sousa MH, Silva NN. Comparação de softwares para análise de dados de levantamentos complexos. Rev. Saude Publica. 2000;34(6):646-653. 
38. Bakas T, McLennon SM, Carpenter JS, et al. Systematic review of health-related quality of life models. Health Qual Life Outcomes. 2012;16(10):134.

39. Cohen J, Cohen P, West SG, Applied Multiple Regression/Correlation Analysis for the Behavioral Sciences,3rd edn. Routledge, UK; 2013

40. Fournier DA. Skaug HJ, Ancheta J, et al. AD Model Builder: using automatic differentiation for statistical inference of highly parameterized complex nonlinear models. Optim. Methods Softw. 2012;27:233-249.

41. Petrini C. Helsinki 50 years on. Clin Ter. 2014;165(4):179-181.

42. Novoa PC. What changes in Research Ethics in Brazil: Resolution no. 466/12 of the National Health Council. Einstein (São Paulo). 2014;12(1):7-9.

43. Cabrera MAS, Filho JW. Obesidade em idosos: prevalência, distribuição e associação com hábitos e co-morbidades. Arq Bras Endocrinol Metabol. 2001;45(5):494-501.

44. Silveira EA, Kac G, Barbosa LS. Prevalência e fatores associados à obesidade em idosos residentes em Pelotas, Rio Grande do Sul, Brasil: classificação da obesidade segundo dois pontos de corte do índice de massa corporal. Cad Saude Publica. 2009;25(7):1569-1577.

45. Crimmins EM, Kim JK, Auró SA. Gender differences in health: results from SHARE, ELSA and HRS. Eur J Public Health. 2011;21(1):81-91.

46. Campolina AG, Adami F, Santos JLF, et al. Effect of eliminating chronic diseases among elderly individuals. Rev Saude Publica. 2013;47(3):514-522.

47. Marengoni A, Angleman S, Melis R, et al. Aging with multimorbidity: a systematic review of the literature. Ageing Res Rev. 2011;10(4):430-439.

48. Wilson PWF, Kannel WB. Obesity, Diabetes and Risk of Cardiovascular Disease in the Elderly. Am J Geriatr Cardiol. 2002;11(2):119-124.

49. Weiss A, Beloosesky Y, Boaz M, et al. Body mass index is inversely related to mortality in elderly subjects. J Gen Intern Med. 2008;23(1):19-24.
50. Silva NLS, Karnikowiski MGO, Tavares AB, et al. Associação entre sarcopenia, obesidade sarcopênica e força muscular com variáveis relacionadas de qualidade de vida em idosas. Brazilian J Phys Ther. 2012;16(5):360-367.

51. Flegal KM, Kit BK, Orpana H, et al. Association of all-cause mortality with overweight and obesity using standard body mass index categories: a systematic review and meta-analysis. JAMA. 2013;309(1):71-82.

52. Flegal KM, Zadeh KK. Overweight, mortality and survival. Obesity (Silver Spring). 2013;21(9):1744-1745.

53. Topp CW, Østergaard SD, Søndergaard S, et al. The WHO-5 Well-Being Index: a systematic review of the literature. Psychother Psychosom. 2015;84(3):167-176.

54. Wu AW, Hays RD, Kelly S, et al. Applications of the Medical Outcomes Study health-related quality of life measures in HIV/AIDS. Qual Life Res. 1997;6(6):531-554

55. Kalache A, Gatti A. Active ageing: a policy framework. Adv Gerontol. 2003;11:7-18.

56. Cameron ID, Fairhall N, Langron C, et al. A multifactorial interdisciplinary intervention reduces frailty in older people: randomized trial. BMC Med. 2013;11:65.

57. Kanwar A, Singh M, Lennon R, et al. Frailty and health-related quality of life among residents of long-term care facilities. J Aging Health. 2013;25(5):792-802

58. Linda JW, Christine B, Behrman J, et al. New Directions in the Sociology of Aging. Panel on New Directions in Social Demography, Social Epidemiol-ogy, and the Sociology of Aging. National Academies Press. Washington, USA; 2013.

59. Wensing M. Research methods from social science can contribute much to the health sciences. J Clin Epidemiol. 2008;61(6):519-520. 